Received Date : 21-Mar-2016

Revised Date : 22-Jun-2016

Accepted Date : 24-Jun-2016

Article type : : - Brief Communication

COCCIDIOIDOMYCOSIS TRANSMISSION THROUGH ORGAN TRANSPLANTATION: A REPORT OF THE OPTN AD HOC DISEASE TRANSMISSION ADVISORY COMMITTEE

S Kusne $^{1}$, S Taranto ${ }^{2}$, S Covington ${ }^{2}$, D.R. Kaul ${ }^{3}$, E.A. Blumberg ${ }^{4}$, C Wolfe $^{5}$, and M Green $^{6}$

1 Division of Infectious Disease, Mayo Clinic in Arizona, Phoenix, AZ

2

United Network for Organ Sharing, Richmond, VA. 3 Department of Internal Medicine, Division of Infectious Disease, University of Michigan Medical School, Ann Arbor, MI. 4 Department of Medicine, Division of Infectious Disease, Perelman School of Medicine at the University of Pennsylvania, Philadelphia, PA. 5 Division of Transplant Infectious Disease, Duke University Medical Center, Durham, NC 6 Department of Pediatrics and Surgery, Division of Pediatric Infectious Diseases, University of Pittsburgh Medical School, Pittsburgh, PA.

Corresponding author:

Shimon Kusne

This is the author manuscript accepted for publication and has undergone full peer review but has not been through the copyediting, typesetting, pagination and proofreading process, which may lead to differences between this version and the Version of Record. Please cite this article as doi: $\underline{10.1111 / a j t .13950}$

This article is protected by copyright. All rights reserved 
(phone) : 480-342-0115 (fax) :

480-342-0689 e-mail:

kusne.shimon@mayo.edu

$+$

Running Title: Donor Derived Coccidioidomycosis

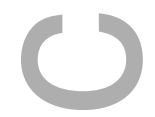

Abbreviations: DTAC, Disease Transmission Advisory Committee; PDDTE, potential donor-derived transmission events; OPTN, Organ Procurement and Transplantation Network

\section{ABSTRACT \\ ABSTRACT}

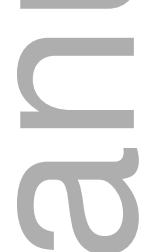

Donor-derived coccidioidomycosis has caused unexpected morbidity and mortality in transplant recipients. All proven or probable reports of donor-derived coccidioidomycosis to the Disease Transmission Advisory Committee (DTAC) between 2005 and August, 2012 were reviewed. Six reports of proven or probable coccidioidomycosis were discovered. In 4 of 6 , the infection was first detected at autopsy in the recipient. In 2 cases it was first identified in the donor. Twenty-one recipients received organs from these 6 donors. Transmission occurred in $43 \%$ at a median of 30 days post-transplant with a mortality rate of $28.5 \%$. Eleven recipients received pre-emptive antifungals, 7 did not receive treatment, and treatment information was not reported for 3 recipients. Five of 7 who did not receive prophylaxis/treatment expired and all 11 who received early therapy survived. Six deaths occurred 14 to 55 days after transplant; median of 21 days. For exposed recipients, donor-derived coccidioidomycosis is a significant cause of morbidity and mortality. Evidence of infection in one recipient should prompt immediate evaluation for treatment of all other recipients from the same donor as preemptive treatment was effective. Further studies are needed to decide whether all donors from endemic areas should have routine serologic screening. 


\section{Introduction}

When recognized in the donor and not treated in recipients, donor-derived coccidioidomycosis has been a significant cause of unexpected morbidity and mortality after organ transplantation, and fatal outcomes have been reported [1-7]. In the US most cases involve donors from Organ Procurement and Transplantation (OPTN) region 5, an area that includes New Mexico, Arizona, Utah, Nevada, and California. The optimal management and the efficacy of preventative antifungal treatment for exposed recipients are not well defined. The purpose of this study was to review all the cases of potential transmission of coccidioidomycosis reported to the Disease Transmission Advisory Committee (DTAC) and examine possible strategies to prevent donor-derived coccidioidomycosis.

\section{Materials and Methods}

All reports of potential donor-derived transmission events (PDDTEs) to DTAC between January 2005 and August 2012 were searched for coccidioidomycosis. Coccidioidomycosis was diagnosed based on any positive serology test, positive pathology or positive culture for Coccidioides immitis/posadasii in donors and/or recipients. The definition of donor-derived infection was based on the previously published DTAC categories related to donor derivation and include proven, probable, possible, unlikely, intervention without documented transmission, and excluded $[8,9]$. Only PDDTEs classified as proven or probable as determined by review of DTAC were analyzed. DTAC collects information under confidential medical peer review, and thus demographic and clinical information was summarized to prevent recognition of a particular case or a particular institution.

A Pubmed and Medline search of English language journals from 1950-2013 was performed to find case reports of donor-derived coccidioidomycosis. The search keywords included Coccidioides immitis/posadasii, Coccidioides Species, Coccidioidomycosis, Valley fever, transmission, solid organ transplant. The demographic and clinical data of these cases were tabulated. 


\section{Results}

Between January 2005 and August 2012, DTAC investigated 14 donors implicated in PDDTEs for transmission of coccidioidomycosis; $6(43 \%)$ were classified as proven $(n=5)$ or probable $(n=1)$ transmissions from donors to at least one recipient. Of the 6 coccidioidomycosis donor transmissions, 4 were first diagnosed in a recipient at the time of autopsy and the remaining 2 cases were first detected in the donor after the transplant operation. Coccidioidomycosis transmission occurred in 9 (43\%) of 21 exposed organ recipients (including the 4 fatal index recipient cases) at a median of 30 days (range 6-64) after the transplant operation, and 6 (67\%) of 9 recipients developed fungal dissemination to multiple organs. The mortality at four months follow up after transplantation was 6/21 (28.5\%) exposed recipients; none of the 11 exposed recipients who received preventative or early treatment died (Figure 1). The 6 deaths occurred at a median of 21 days after transplantation (range 14-55). Five of the 6 donors with proven or probable transmission were from OPTN region 5 (endemic area) and 11 of 14 PDDTE donors reviewed were also from OPTN region 5.

Our review of the literature identified 7 donors of organs that were placed in 18 organ recipients resulting in $11(61 \%)$ recipients with donor-derived coccidioidomycosis (Table 1). Several of these cases occurred outside the US and others in the US before 2008 (our first DTAC case occurred in 2008), none of these would be duplicated by the DTAC series. Of the recipients with known information, $40 \%$ were female, and median age was 46 years (range 18-66). Donor-derived coccidioidomycosis was recognized at a median of 14 (range 6-60) days after transplantation. The overall mortality was $44.4 \%(8 / 18)$ with $86 \%(7 / 8)$ of these deaths directly attributable to coccidioidomycosis; all 7 deaths had evidence of disseminated coccidioidomycosis to multiple organs $(n=6)$ or the central nervous system $(n=1)$. In the seven deaths, transmission and dissemination occurred after kidney alone $(n=3)$, simultaneous kidney and pancreas $(n=1)$, Kidney-liver $(n=1)$, heart $(n=1)$, and bilateral lung transplantation $(n=1)$. Five of the 7 (71\%) donors had been living in or had visited endemic areas for coccidioidomycosis. One donor was from France, but visited Arizona two months before becoming a donor to a single lung transplant recipient (case 6 in the table). Three donors had evidence of active infection at procurement of organs, two with dissemination to central nervous system with meningitis (case 1 and 2 in the table) and one with evidence of coccidioidomycosis in a hilar lymph node (case 4 in the table).

This article is protected by copyright. All rights reserved 


\section{Discussion}

The use of organ donors from areas endemic for coccidioidomycosis may lead to transmission of this fungal pathogen to organ recipients as illustrated in the published literature and the DTAC experience presented here [1-7]. Donors may have active infection not recognized at their evaluation for organ donation or may have prior infection with contained but viable organisms that reactivate in the setting of recipient immunosuppression. In one series, seropositivity of potential kidney and liver donors in an endemic area was $2.1 \%$ [10]. Also, a living donor may be incubating coccidioidomycosis at the time of evaluation with no symptoms and negative serology but later develop symptoms and become seropositive [10]. As our report illustrates, for exposed recipients the risk of significant morbidity and mortality is high, and poor outcomes typically occur soon after transplantation allowing little time for diagnosis and treatment once symptoms occur. Our data suggest, however, that preventative treatment with anti-fungal drugs of exposed individuals is very effective in preventing disseminated disease and death compared to those exposed recipients who were not treated. Thus, we believe that evidence of coccidioidomycosis infection in one recipient should prompt initiation of treatment in all other recipients preemptively. Similarly, if serologic or other evidence of coccidioidomycosis in the donor becomes available after transplant, we also recommend evaluation of the need for treatment of all recipients of organs from this donor.

Our data do not address the appropriate duration, dose, or drug that should be used as part of preventative therapy. The American Society of Transplantation's Infectious Disease Community of Practice provides some expert opinion regarding these questions [11]. The guidelines recommend that recipients of an organ from a donor with pulmonary coccidioidomycosis should receive fluconazole 400 mg daily for 3-12 months if non-lung organ recipient with an option of lifelong therapy at $200 \mathrm{mg}$ daily after the first year. For lung recipients of organs from donors with pulmonary coccidioidomycosis, the recommendation is lifelong fluconazole, $400 \mathrm{mg}$ daily. All recipients of donors with evidence of extrapulmonary coccidioidomycosis should receive lifelong fluconazole $400 \mathrm{mg}$ daily, with careful laboratory, clinical, and radiological follow up if prophylaxis is discontinued. If a donor is seropositive without a documented focus of infection, the lung recipient should receive $400 \mathrm{mg}$ of fluconazole daily for life, and a non-lung organ recipient $400 \mathrm{mg}$ daily for 12 months and $200 \mathrm{mg}$ thereafter.

This article is protected by copyright. All rights reserved 
An important issue is the potential role of universal or targeted serological donor screening in endemic regions in order to identify donors at risk of transmitting coccidioidomycosis. Information regarding endemicity of coccidioidomycosis was obtained by skin test [12]. In the United States, OPTN region 5 (California, Arizona, Nevada, Utah, New Mexico) and Southern Texas is the primary geographic region endemic for coccidioidomycosis. Within this region, parts of Arizona and California are at a particularly high risk (example, Sonoran desert in Arizona, and San Joaquin valley in California) [13, 14]. Because of the risk of "imported" cases, clinicians should also be aware of the epidemiology outside the US [12]. Countries with endemic areas include Mexico, Guatemala, Honduras and other countries in South and Central America [12]. The predictably elevated risk for prior infection with coccidioidomycosis within endemic region suggests that recipients of organs from donors who live in Region 5 might benefit from targeted serologic screening of donors. This recommendation might be extended to potential donors who visited or lived in the past in Region 5 but were not residing there at the time of donation. While clearly cases of donor-derived transmission of coccidioidomycosis have occurred from such donors, the lack of data to differentiate what might be a "high risk" exposure for donors with a history of travel to an endemic region would suggest that screening donors for any transient travel to a high risk region would not likely be cost-effective nor could not it be reliably implemented. Further st udies are needed to determine whether all donors in endemic areas (e.g. OPTN region 5) should have routine coccidioidomycosis serology testing. In the absence of such data, it is worth noting that one of the authors of this report who works in an endemic area for coccidioidomycosis uses routine prophylaxis for coccidioidomycosis in all organ recipients for 12 months together with serological screening of all donors and recipients. Seronegative organ recipients are usually rechecked yearly, or if there is a clinical indication. This center is currently using universal prophylaxis because of failure of targeted prophylaxis with diagnosis of new cases of coccidioidomycosis within one year after transplantation [15].

The OPTN/DTAC has published guidance regarding testing of potential living donors for seasonal and endemic infections [16]. A consideration for coccidioidomycosis screening include those who reside or stayed in endemic areas, those with symptoms or signs of active infection and those with history of coccidioidomycosis [16]. Implementation of epidemiologic risk based screening will not likely eliminate all cases of donor derived coccidioidomycosis in the United States. It is unrealistic to believe that Organ Procurement Organizations would be able to get a reliable travel history on all potential donors. Additionally, in some reported cases there is no clear residence or travel to endemic areas in or outside 
the US. Recently three non-transplant cases of coccidioidomycosis reported from Washington State had no history of residence or travel to endemic area [17]. Soil was sampled and investigated by the CDC's Mycotic Disease Laboratory by PCR. C. immitis/posadasii was found in 6 of 22 soil samples, and viable fungus was isolated in 4 samples [18]. This shows that coccidioidomycosis may be found outside the known endemic areas, although currently the major risk area remains the Southwestern United States.

This study has a number of important limitations. In some cases the information was incomplete; furthermore, the diagnostic methods and treatments varied between treating medical centers. The DTAC reporting system is required but passive, and all cases of donor-derived coccidioidomycosis or donor infection with coccidioidomycosis may not have been reported. Thus, we are not able to reliably assess the risk faced by a recipient of an infected donor, especially one with latent infection. As DTAC reports are collected under confidential peer review, information is reported in aggregate. Thus no attempt was made to compare our information and the information obtained from review of the literature. We cannot confirm or exclude the possibility of duplication between DTAC records and cases reported in the literature during the same time period. Nevertheless, viewing these confirmed donor derived cases in the aggregate provides a useful alert for transplant professionals who may not be fully aware of this risk:

In summary, data from the review of the DTAC experience and the literature demonstrate that donor-derived coccidioidomycosis can be life threatening and typically occurs soon after transplantation. Preventative antifungal treatment, however, may be life-saving if administered to exposed recipients. Efficient communication between OPOs and transplant centers is critical to this process. While our data does not specifically address the value of universal or targeted donor testing in endemic areas (or those with previous residence in endemic areas), the lethality of donor-derived coccidioidomycosis combined with the availability of effective preventative therapy emphasizes the need for a careful evaluation of the potential benefit of such a practice. Clinically appropriate screening and prophylaxis are crucial to prevent coccidioidomycosis in endemic areas where there is potential constant exposure.

\section{Acknowledgments}

The authors would like to thank Amber Wilk for her assistance with the manuscript. 


\section{Disclosure}

The authors of this manuscript have no conflicts of interest to disclose as described by the American Journal of Transplantation.

\section{Figure Legends}

Figure 1: Outcome of recipients exposed to coccidioidomycosis

\section{References}

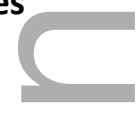

1. Blodget, E., et al., Donor-derived Coccidioides immitis fungemia in solid organ transplant recipients. Transpl Infect Dis, 2012. 14(3): p. 305-10.

2. Brugiere, O., et al., Coccidioidomycosis in a lung transplant recipient acquired from the donor graft in France. Transplantation, 2009. 88(11): p. 1319-20.

3. Carvalho, C., et al., Cerebral coccidioidomycosis after renal transplantation in a non-endemic area. Transpl Infect Dis, 2010. 12(2): p. 151-4.

4. Dierberg, K.L., et al., Donor-derived organ transplant transmission of coccidioidomycosis. Transpl Infect Dis, 2012. 14(3): p. 300-4.

5. Miller, M.B., R. Hendren, and P.H. Gilligan, Posttransplantation disseminated coccidioidomycosis acquired from donor lungs. J Clin Microbiol, 2004. 42(5): p. 2347-9.

6. Tripathy, U., et al., Donor transfer of pulmonary coccidioidomycosis in lung transplantation. Ann Thorac Surg, 2002. 73(1): p. 306-8.

7. Wright, P.W., et al., Donor-related coccidioidomycosis in organ transplant recipients. Clin Infect Dis, 2003. 37(9): p. 1265-9.

8. Garzoni, C. and M.G. Ison, Uniform definitions for donor-derived infectious disease transmissions in solid organ transplantation. Transplantation, 2011. 92(12): p. 1297-300. 
9. Ison, M.G. and M.A. Nalesnik, An update on donor-derived disease transmission in organ transplantation. Am J Transplant, 2011. 11(6): p. 1123-30.

10. Blair, J.E. and D.C. Mulligan, Coccidioidomycosis in healthy persons evaluated for liver or kidney donation. Transpl Infect Dis, 2007. 9(1): p. 78-82.

11. Singh, N., et al., Donor-derived fungal infections in organ transplant recipients: guidelines of the American Society of Transplantation, infectious diseases community of practice. Am J Transplant, 2012. 12(9): p. 2414-28.

12. Brown, J., et al., Coccidioidomycosis: epidemiology. Clin Epidemiol, 2013. 5: p. 185-97.

13. Sondermeyer, G., et al., Coccidioidomycosis-associated hospitalizations, California, USA, 20002011. Emerg Infect Dis, 2013. 19(10): p. 1590-7.

14. Centers for Disease, C. and Prevention, Increase in reported coccidioidomycosis--United States, 1998-2011. MMWR Morb Mortal Wkly Rep, 2013. 62(12): p. 217-21.

15. Kahn, A., E.J. Carey, and J.E. Blair, Universal fungal prophylaxis and risk of coccidioidomycosis in liver transplant recipients living in an endemic area. Liver Transpl, 2015. 21(3): p. 353-61.

16. OPTN/UNOS/DTAC. Recognizing seasonal and geographically endemic infections in organ donors: considerations during living donor evaluation. 2014; Available from: https//optn.transplant.hrsa.gov/media/1138/seasonal disease guidance.pdf.

17. Marsden-Haug, N., et al., Coccidioidomycosis acquired in Washington State. Clin Infect Dis, 2013. 56(6): p. 847-50.

18. Marsden-Haug, N., et al., Coccidioides immitis identified in soil outside of its known range Washington, 2013. MMWR Morb Mortal Wkly Rep, 2014. 63(20): p. 450.

This article is protected by copyright. All rights reserved 


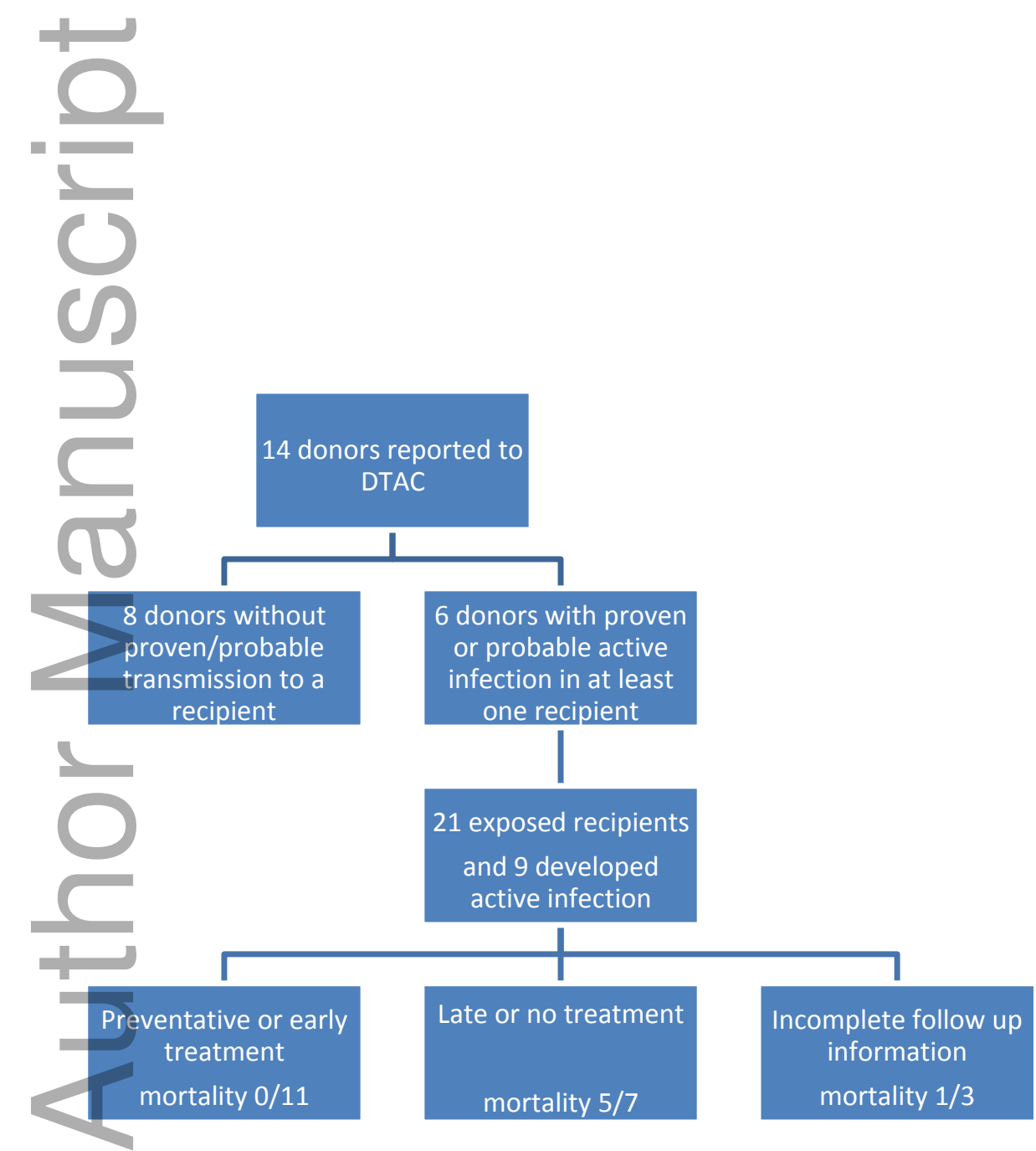

Figure

This article is protected by copyright. All rights reserved 


\begin{tabular}{|c|c|c|c|c|c|c|c|c|c|c|}
\hline Case & $\begin{array}{l}\text { Donor } \\
\text { Demog }\end{array}$ & Donor History and risk & Recip & Recip Organ & $\begin{array}{l}\text { Recip } \\
\text { Age/Sex }\end{array}$ & $\begin{array}{l}\text { Recip } \\
\text { Race }\end{array}$ & $\begin{array}{l}\text { Fungal Prophylaxis } \\
\text { or early treatment }\end{array}$ & Outcome & Cocci Death/Outcome & Comment \\
\hline \multirow[t]{3}{*}{1 [1] } & \multirow{3}{*}{$\begin{array}{l}52 \mathrm{~F} \\
\text { AfAm }\end{array}$} & \multirow{3}{*}{$\begin{array}{l}\text { Had been living in Los Angeles, } \\
\text { confusion, abnormal CSF, abnormal } \\
\text { brain MRI with hydrocephalus, } \\
\text { serum CF is 1:4, liver bx at } \\
\text { procurement with granulomas }\end{array}$} & 1 & heart & $66 \mathrm{M}$ & His & no & III day 16 , died & Yes, diss multiple organs & \multirow{3}{*}{$\begin{array}{l}\text { Donor at time procurement } \\
\text { with cocci meningitis }\end{array}$} \\
\hline & & & 2 & $2^{\text {nd }}$ kidney & $40 \mathrm{M}$ & AfAm & no & III day 13 , died & $\begin{array}{l}\text { Yes, diss multiple organs, also } \\
\text { kidney sbscess }\end{array}$ & \\
\hline & & & 3 & $\begin{array}{l}\text { Kidney-liver, } \\
\text { previous } \\
\text { living liv }\end{array}$ & $23 \mathrm{M}$ & His & $\begin{array}{l}\text { No but treated D14 } \\
\text { vori, then ampho B, } \\
\text { then flu }\end{array}$ & $\begin{array}{l}\text { III day 14, Survived, } \\
\text { liver bx granulomas } \\
\text { and spherules }\end{array}$ & $\begin{array}{l}\text { Diss to liver, lung, blood, CF at } 3 \\
\text { months is 1:64 }\end{array}$ & \\
\hline \multirow[t]{3}{*}{$2[2]$} & \multirow[t]{3}{*}{$\begin{array}{l}36 \mathrm{M}, \\
\text { AfAm }\end{array}$} & \multirow{3}{*}{$\begin{array}{l}\text { Presented with headaches, had } \\
\text { cocci meningitis, CF was 1:32. } \\
\text { Previous treated diss cocci in AZ }\end{array}$} & 1 & liver & $46 \mathrm{M}$ & w & $\begin{array}{l}\text { No, treated D14 flu, } \\
\text { then ampho B }\end{array}$ & III day 13 , died & $\begin{array}{l}\text { Yes, diss to multiple organs, } \\
\text { including liver }\end{array}$ & \multirow{3}{*}{$\begin{array}{l}\text { Donor in AZ } 1995-2000 \text { and } \\
\text { diagnosed with disseminated } \\
\text { cocci in } 1996 \text { to skin and bon }\end{array}$} \\
\hline & & & 2 & kidney & $28 \mathrm{M}$ & AfAm & No, treat D19 flu & III day 11, died & $\begin{array}{l}\text { Yes, diss to multiple organs } \\
\text { including kidney, pre-Tx CF was } \\
\text { negative }\end{array}$ & \\
\hline & & & 3 & kidney & $58 \mathrm{~F}$ & AfAm & $\begin{array}{l}\text { No but given itra } 200 \\
\text { mg bid for } 3 \text { mos }\end{array}$ & $\begin{array}{l}\text { Asymptomatic, } \\
\text { survived }\end{array}$ & & \\
\hline $3[3]$ & $\begin{array}{l}22 \mathrm{M} \\
\text { AfAm }\end{array}$ & $\begin{array}{l}\text { Immigrated to the US from Jamaica } \\
\text { in 2001to non-endemic area }\end{array}$ & 1 & kidney & $19 M$ & AfAm & $\begin{array}{l}\text { No but treated D30 } \\
\text { vori, then liposomal } \\
\text { ampho B, then flu }\end{array}$ & III day 29 , survived & $\begin{array}{l}\text { Pos cocci in lung and blood, serology } \\
\text { positive at day } 59 \text { with CF of 1:4 }\end{array}$ & \\
\hline
\end{tabular}

This article is protected by copyright. All rights reserved 


\begin{tabular}{|c|c|c|c|c|c|c|c|c|c|c|}
\hline & & \multirow{4}{*}{0} & 2 & $\begin{array}{l}\text { Kidney } \\
\text { pancreas }\end{array}$ & $45 \mathrm{~F}$ & W & No, micafung D35 & III day 26 , died & Yes, diss lung and blood & \\
\hline & & & 3 & liver & $63 F$ & W & $\begin{array}{l}\text { Yes flu, and D35 on } \\
\text { fluc }\end{array}$ & survived & $\begin{array}{l}\text { Ill day 51, developed bil lung } \\
\text { nodules, negative serology }\end{array}$ & \\
\hline & & & 4 & Bil lung & $62 \mathrm{~F}$ & W & Yes, vori & survived & Day 53 serology CF 1:2 & \\
\hline & & & 5 & heart & $18 \mathrm{M}$ & AfAm & No, D53 flu & died & $\begin{array}{l}\text { No, sudden cardiac death, CF day } 56 \\
\text { negative }\end{array}$ & \\
\hline $4[4]$ & $\mathrm{F}$ & $\begin{array}{l}\text { Resided in AZ, hilar lymph node } \\
\text { was positive for cocci, he liked to } \\
\text { hike }\end{array}$ & 1 & Bil lung; & $21 \mathrm{M}$ & W & $\begin{array}{l}\text { No but treated, D6 } \\
\text { flu }\end{array}$ & III day 6, survived & & $\begin{array}{l}\text { 1-cm firm level } 4 \text { hilar lymph } \\
\text { node found at organ harvest } \\
\text { positive for cocci }\end{array}$ \\
\hline $5[5]$ & 30 & $\begin{array}{l}\text { Resident of non-endemic area, } \\
\text { visited Mexico } 2 \text { years earlier }\end{array}$ & 1 & Bil lung & 61 & & no & III first week, died & Yes, diss multiple organs & \\
\hline $6[6]$ & & $\begin{array}{l}\text { France resident, visited AZ few } \\
\text { months before donation }\end{array}$ & 1 & Single lung & $58 \mathrm{M}$ & France & Yes, itra & survived & $\begin{array}{l}\text { Yes, diss multiple organs, also } \\
\text { kidney sbscess }\end{array}$ & \\
\hline $7[7]$ & $38 / F$ & Not known & 1 & Kidney & $62 M$ & Portugal & no & died & $\begin{array}{l}\text { Diss to liver, lung, blood, CF at } 3 \\
\text { months is } 1: 64\end{array}$ & $\begin{array}{l}\text { No travel history was obtained } \\
\text { on donor and no pretx serology }\end{array}$ \\
\hline & & & 2 & $2^{\text {nd }}$ kidney & & Portugal & no & survived & $\begin{array}{l}\text { Yes, diss to multiple organs, } \\
\text { including liver }\end{array}$ & was obtained \\
\hline & & & 3 & Liver & & Portugal & no & survived & $\begin{array}{l}\text { Yes, diss to multiple organs } \\
\text { including kidney, pre-Tx CF was } \\
\text { negative }\end{array}$ & \\
\hline & & & 4 & Heart & & Portugal & no & survived & & \\
\hline
\end{tabular}

\section{Table 1: Published cases of donor-derived coccidioidomycosis and outcome}

Pos=positive, AfAm=African American, M=male, F=female, Demo=Demographics, Recip=recipient, Bil=bilateral, His=Hispanic, W=white, Flu=fluconazole, Vori=voriconazole, Itra=itraconazole, diss=disseminated

This article is protected by copyright. All rights reserved 


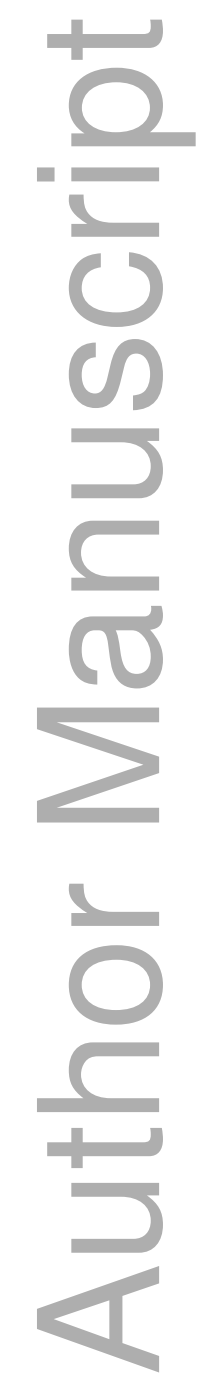

This article is protected by copyright. All rights reserved 